\title{
Effect of Kinesio Taping on Grasp and Release in Children with Spastic Hemiparetic Cerebral Palsy: A Pilot Study
}

\author{
AHMED A. ZAHR EL-DIN, M.Sc.*; ELHAM E. SALEM, Ph.D.*; SHOROUK EL-SHENNAWY, Ph.D.* and \\ KAMEL H. MORSY, M.D.** \\ The Department of Pediatric Physical Therapy, Faculty of Physical Therapy, Cairo University* and \\ The Department of Neurology, Faculty of Medicine, Cairo University**
}

\begin{abstract}
Background: Cerebral Palsy (CP) children have motor dysfunction due to non-progressive brain damage. Hemiplegic cerebral palsy children usually have marked hand involvement with limited active wrist extension and excessive thumb adduction and flexion which appears from infancy. Various techniques are generally used in the course of $\mathrm{CP}$ management. A recent method such as taping is frequently used in pediatrics rehabilitation clinics. It is easy to apply and inexpensive and can be easily removed or changed according to therapy objects. In CP it corrects postural misalignment enhance joint stability, activate weak muscle and manage spasticity.
\end{abstract}

Aim of Study: To determine the short term effect of kinesio taping on hand functions especially grasp and release in the children with spastic hemiparetic cerebral palsy.

Participants and Methods: Eleven spastic hemiparetic cerebral palsied children (2-7 years old) of both sexes with mild hand and/or wrist spasticity (grade 1 to $1+$ ) according to the Modified Ashowrth Scale, and had impaired hand functions level II, III and IV according to Manual Ability Classification System (MACS) participated in this study. Participants received kinesio tape for wrist and thumb in addition to the standard conventional physical therapy program (2-3 hours per week). Participants were evaluated before and after four weeks using the Grasping subtests of the Quality of Upper Extremity Skills Test (QUEST) and Peabody Developmental Motor Scale (PDMS).

Results: After Four weeks of intervention results showed that no significant changes post treatment application when compared with corresponding pretreatment for the PDMS ( $p$ value $=0.096)$ and QUEST $(p$-value $=0.052)$ scores.

Conclusion: These results suggested that four weeks Kinesio taping was not effective in improving the hand functions of spastic hemiparetic cerebral palsy children.

Key Words: Cerebral palsy - Hemiplegia - Kinesio taping Hand-Grasp-Release.

Correspondence to: Dr. Ahmed A. Zahr El-Din, E-Mail: dr.ahmedzahr@yahoo.com

\section{Introduction}

Cerebral palsy describes a group of permanent disorders of the development of movement and posture, causing activity limitations that are attributed to non-progressive disturbances that occurred in the developing fetal or infant brain. These motor disorders of $\mathrm{CP}$ are often accompanied by disturbances of sensation, perception, cognition, communication, and behavior; by epilepsy, and by secondary musculoskeletal problems [1].

Hemiplegic cerebral palsy children usually have marked hand involvement with limited active wrist extension and excessive thumb adduction and flexion which appears from infancy. This can lead to progressive abnormalities of the motor system development. Also, disturbances of somatosensory and visual function and developmental disregard contribute to the difficulties with hand use. Contractures may occur from the progressive soft tissue and bony changes, which further limit function in a vicious cycle [2].

Hemiplegic cerebral palsy children often have compromization in the effective use of the arm and hand to reach, grasp, release, and manipulate. Early intervention could help to improve these manifestations, however, the precise nature and appropriateness of the intervention must be carefully considered [3].

Adhesive taping is one of the therapeutic modalities used in cerebral palsy. In 1973 kinesio tape with elastic properties was developed by Kenzo Kase, depending on that an external component could aid the functions of muscles and other tissues. Taping is an increasingly popular adjuvant therapy because it is easy to apply and inexpensive, and it 
can be easily removed or changed according to therapy objectives [4].

The stretch applied on the tape provides a pulling force on the skin and creates more space by lifting the fascia and soft tissue, and this improves communication with mechanoreceptors and increases the number of motor units recruited [5]

\section{Significance of study:}

This study was designed as there was little evidence about the effect of Kinesio taping on grip strength and its role as an adjunctive technique of physical therapy in managing grasping and release and improving hand functions in spastic hemiparetic cerebral palsied children.

So, the aim of this study was to determine the short term effect of kinesio taping on hand functions especially grasp and release in children with spastic hemiparetic cerebral palsy.

\section{Material and Methods}

Eleven children participated in this study. Children were selected mainly from the outpatient clinic of the Faculty of Physical Therapy, Cairo University, in addition to outpatient clinic of Abo Al-Reesh Hospital; from October 2016 to December 2016. Children were selected according to these criteria:

\section{- Inclusion criteria:}

- Children were medically diagnosed as spastic hemiparetic cerebral palsy.

- Age was ranged from 2 to 7 years.

- Both sexes were included.

- Children had mild hand and/or wrist spasticity (grade 1 to $1+$ ) according to the Modified Ashowrth Scale.

- Children had impaired hand functions level II, III and IV according to Manual Ability Classification System (MACS).

- They were having stable clinical status.

- Exclusion criteria:

- Visual or auditory problems presented.

- Skin diseases or irritation or known skin sensitivity for kinesio tape presented.

- Fixed deformities in hand presented.

- Children had severe sensory and motor loss in the area to be taped.

- Surgical interventions have been done in the upper extremity.
This study was conducted under the guidelines and the approval of Research Ethical Committee of the Faculty of Physical Therapy, Cairo University (No. P.T. REC/012/001455). The parents signed a consent form authorizing the child's participation.

\section{Study design:}

This was a pilot study to determine short term effect of kinesio taping on hand functions in children with spastic hemiparetic cerebral palsy. Kinesio Tape was applied for wrist and thumb in addition to the standard conventional physical therapy program (30-45 minutes per session; 2-3 sessions weekly).

All children were evaluated before and after the suggested period of the physical therapy program which was four weeks to evaluate the short term effect of the kinesio tape on grasp and release. Evaluation was done using the Grasping subtests of the Quality of Upper Extremity Skills Test (QUEST) and Peabody Developmental Motor Scale (PDMS).

\section{Interventions:}

- Quality of Upper Extremity Skills Test (QUEST):

The upper limb movement was assessed using the Quality of Upper Extremity Skills Test (QUEST). Its items were designed to detect clinical changes in movement prior to changes in skills. It also discriminates the quality of movement, measures components of hand function, and provides information about movement and postural responses. Only grasp items of the dissociated movements subtest and grasp subtest were used to evaluate children ability to grasp and release objects.

\section{- Peabody Developmental Motor Scale (PDMS):}

General developmental framework has been adopted in PDMS and it contains both qualitative (refers to how well child performs the skill) and quantitative (refers to how many skills child is able to perform) approach to assessment. Only Grasping subtest was used in this study to assess the fine motor abilities of the children.

The QUEST measures components of hand function as well as quality of movement, and has high correlation with the PDMS. The grasp domain on the QUEST correlates highly with all areas of the PDMS. The QUEST provides information about the quality of movement and postural responses while the PDMS measures task achievement. Therefore, both measures were used for a more comprehensive assessment [6] 


\section{- The standard conventional physical therapy pro- gram:}

Participants took their ordinary physical therapy rehabilitation program at the Outpatient Clinics of the Faculty of Physical Therapy, Cairo University and Abo Al-Reesh Hospitals which were 30-45 minutes per session; 2-3 sessions weekly. Cerebral palsy children experience posture, balance, function and mobility challenges of varying degrees. Physical therapy improves strength, mobility, posture, balance and flexibility and focuses on basic mobility such as standing, walking, climbing stairs, reaching, grasping and in-hand manipulation is a key element in management of cerebral palsy children. According to the child's needs, exercises were delivered and included:

- Neurodevelopmental Treatment (NDT): This approach aims to facilitate typical motor development and function and to prevent development of secondary impairments due to muscle contractures, joint and limb deformities.

- Muscle stretching exercises: Used to maintain length and flexibility of all muscles susceptible to be short.

- Muscle strengthening exercises: Aimed to increase the power of weak antagonist muscles and of the corresponding spastic agonists and to provide the functional benefits of strengthening in children with $\mathrm{CP}$.

- Occupational therapy: Focused on daily life activities, such as feeding, dressing, toileting, grooming, and transfers by focusing on the upper body. Occupational therapy will be integrated in these sessions. And there are examples of these activities: Putting marbles into bottle, art projects, ball play, building tower with blocks, buttoning, unbuttoning, zipping activities and everyday tasks which include home, school and community tasks.

\section{- Kinesio Tape:}

A test piece (2-3 inches) of Kinesio Tape with no tension was applied prior to any therapeutic taping and left on for 24 hours or unless the patient noticed any skin irritation (visual or sensory). Tape left on for 3-5 days. Skin cells sloughed off in approximately 3-5 days which made tape easier to take off. The tape did not left on for any longer than this amount of time to left the skin rest. The skin rested for at least 24 hours after a taping application [7]

At rest, spastic cerebral palsy children forearm is in pronation, with the wrist flexed and thumb adducted. The pronated forearm biomechanically influences the position of their hand for prehension. So, they were taped for wrist extension to support the weak wrist. Thumb extension taping was applied to position the thumb and wrist in a more neutral alignment by the following techniques [8]

- Wrist extension assist: A 1.5 or 2 inch "I" tape was used. Tape length was measured from the metacarpals to the lateral epicondyle. The wrist was extended and the anchor was applied on the dorsum of the hand, over the metacarpals. The wrist was maintained in extension. The proximal anchor of tape was applied on the lateral epicondyle. A space between the tape and forearm was left. Area of greater tension may was targeted by anchoring proximal to the lateral epicondyle, with more tension to tape on specific area over wrist. The wrist was flexed as the therapist rubs the tape down over dorsum of the forearm. The tape assisted with active wrist extension.

- Thumb extension assist: A 1 inch or 1.5 inch "I" tape was used. The tape length from the Interphalangeal (IP) joint of the thumb to distal third of the forearm was measured.

The thumb was positioned into extension and the tape was anchored at the thumb IP joint using the buttonhole technique. The thumb was maintained in extension. Proximal anchor of tape was applied to middle third of interosseous membrane, on dorsal surface of forearm. A space was left between the tape and forearm. The thumb was flexed as the therapist rub down the tape over the thumb and the dorsum of the forearm.

- Thumb metacarpophalangeal stability taping: A 1/2 Inch or 1/4 inch "I" tape was used to support the joint. An "I" strip was measured around the thumb. Slight flexion at the MCP joint was maintained. The tape was torn in the middle and downward pressure was used with the MCP joint in flexion. No tension applied at the ends of tape and wrap around the joint.

\section{Data analysis:}

Data were analyzed using SPSS advanced statistics (Statistical Package for Social Sciences), Version 21 (SPSS Inc., Chicago, IL). Numerical data were described as mean and standard deviation or median and range. Categorical data were described as numbers and percentages. Data were explored for normality using Kolmogrov-Smirnov test and Shapiro-Wilk test. Paired $t$-test was used for comparison overtime changes. A $p$-value less than or equal to 0.05 were considered statistically significant. All tests were two tailed. 


\section{Results}

The age, gender, side of hemiplegia, MAS and MACS in the studied group are summarized in (Table 1) and mean values and standard deviation comparing hand function changes overtime are shown in (Table 2).

As shown in (Table 1), participants were consisted of 11 children 5 boys and 6 girls, they were 7 right and 4 left hemiplegic with mean age value was $3.8 \pm 1.6$ years $(45.5 \pm 18.7$ months $)$.

Ashowrth scale score (1) was repeated in 4 children with a given percentage of $36.4 \%$ and score $(1+)$ was repeated in 7 children with a given percentage of $63.6 \%$. MACS score (II) was repeated in 3 children with a given percentage of $27.3 \%$, score (III) was repeated in 6 children with a given percentage of $54.5 \%$, and score (IV) was repeated in 2 children with a given percentage of $18.2 \%$.

As shown in (Table 2), the mean value of PDMS pretreatment was 31.7 with SD 9.8 Fig. (1) while mean value of PDMS post treatment was 32.6 with SD 10.6 Fig. (2). Statistically, there was no significant difference in PDMS post-treatment application when compared with corresponding pretreatment value with $p$-value $=0.096$. The mean value of QUEST pretreatment was 74.7 with SD 11.1 Fig. (3) while mean value of QUEST post treatment was 76.8 with SD11.2 Fig. (4). Statistically, there was no significant difference in QUEST post treatment application when compared with corresponding pretreatment value with $p$-value $=0.052$.

Table (1): Age, gender, side of hemiplegia, MAS and MACS in the studied group.

\begin{tabular}{|c|c|c|c|}
\hline & No. & $\%$ & $p$-value \\
\hline $\begin{array}{l}\text { Age (months): } \\
\text { Mean } \pm \text { SD } \\
\text { Range }\end{array}$ & \multicolumn{2}{|c|}{$\begin{array}{c}45.5 \pm 18.7 \\
27-84\end{array}$} & 0.904 \\
\hline $\begin{array}{l}\text { Gender: } \\
\text { Male } \\
\text { Female }\end{array}$ & $\begin{array}{l}5 \\
6\end{array}$ & $\begin{array}{l}45.5 \\
54.5\end{array}$ & 0.188 \\
\hline $\begin{array}{l}\text { Side of hemiple } \\
\text { Rt. } \\
\text { Lt. }\end{array}$ & $\begin{array}{l}7 \\
4\end{array}$ & $\begin{array}{l}63.6 \\
36.4\end{array}$ & 0.497 \\
\hline $\begin{array}{c}M A S: \\
1 \\
1+\end{array}$ & $\begin{array}{l}4 \\
7\end{array}$ & $\begin{array}{l}36.4 \\
63.6\end{array}$ & 0.302 \\
\hline $\begin{array}{l}\text { MACS: } \\
\quad \text { II } \\
\text { III } \\
\text { IV }\end{array}$ & $\begin{array}{l}3 \\
6 \\
2\end{array}$ & $\begin{array}{l}27.3 \\
54.5 \\
18.2\end{array}$ & 1.000 \\
\hline
\end{tabular}

MACS: Done by fisher exact test, $p \leq 0.05$ is considered statistically significant.
Table (2): Mean values and standard deviation comparing hand function changes overtime.

\begin{tabular}{cccc}
\hline & Pre score & Post score & $p$-value \\
\hline PDMS: & & & \\
Mean & 31.7 & 32.6 & 0.096 \\
SD & 9.8 & 10.6 & \\
QUEST: & & & \\
Mean & 74.7 & 76.8 & 0.052 \\
SD & 11.1 & 11.2 & \\
\hline
\end{tabular}

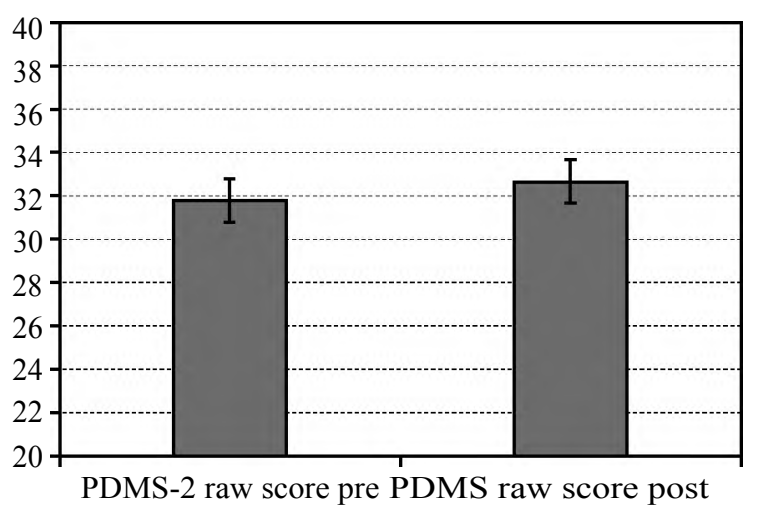

Fig. (1): Mean values and standard deviation of standard PDMS pre among the studied group.

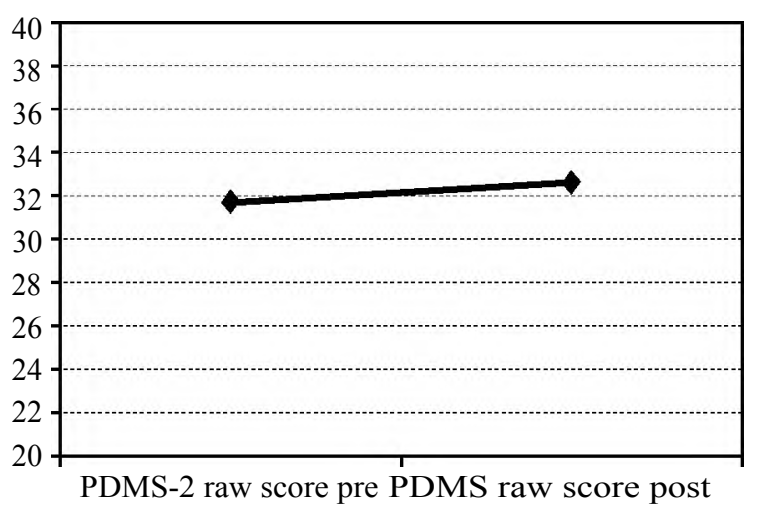

Fig. (2): Mean values of PDMS score pre and post among the studied group.

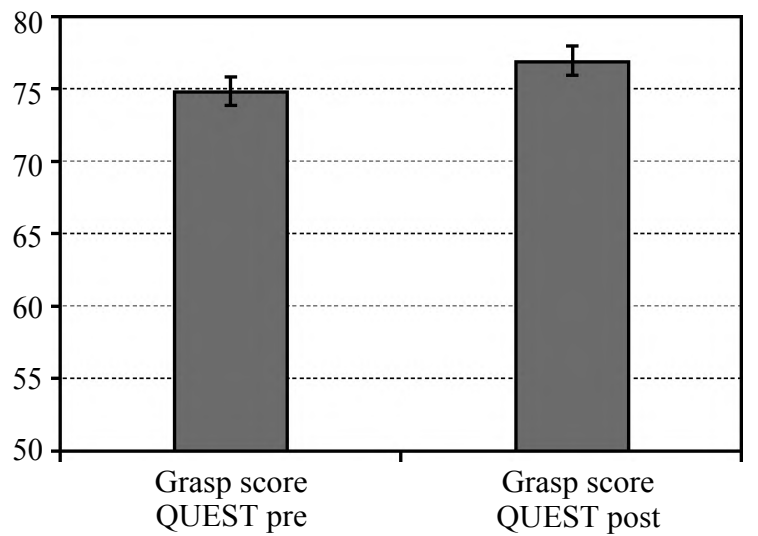

Fig. (3): Mean values and standard deviation of QUEST grasp score pre and post among the studied group. 


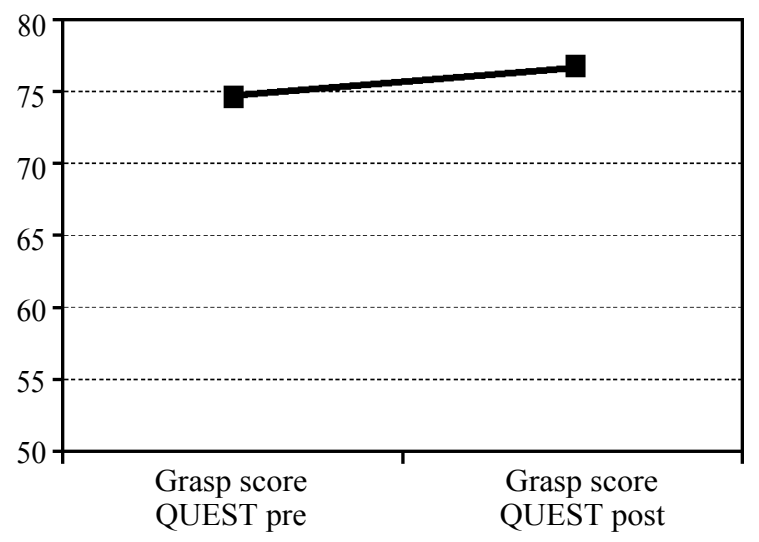

Fig. (4): Mean values of QUEST grasp score pre and post among the studied group.

\section{Discussion}

The present study demonstrated that the application of tape on wrist and thumb to improve grasp and release in children with spastic hemiparetic cerebral palsy was not very effective as no significant improvement was observed during this period.

Many authors $[9-12,14-17,19]$ have discussed the effectiveness of taping on cerebral palsy children mainly spastic hemiplegic and diaplegic types. They applied tape to various regions; upper limb, trunk, abdomen and lower limb with different techniques to cope with the purpose of their study. Most of these studies showed statistically significant changes after tape application in $\mathrm{CP}$ children.

Camerota et al., study aimed to assess quantitatively the short term effects of Neuromuscular Taping (NMT) on the upper limb in a female child with left hemiplegia due to cerebral palsy by applying the tape on cervical level, shoulder and hand only of the plegic upper limb, followed by physical therapy. The results showed that the affected limb improved in terms of movement duration, Average Jerk and Number of Unit Movements indices, indicating a faster, smoother and less segmented movement. Improvements appeared at the ranges of motion of the upper limb joints, both at shoulder and elbow joints [9]. Controversy, the current study applied the tape on wrist and thumb only so, tape application on the whole limb (shoulder, arm, forearm, wrist and hand) could be the reason for this different results.

This probability is supported by the results of Kara et al., study that investigated the long term effects of Kinesio Taping on the body functions and activity by involving thirty children with unilateral spastic CP and tape was applied on Ankle, knee, hip, trunk, shoulder, forearm and wrist for
12 weeks; giving positive results in all assessment tests (WeeFIM, BOTMP, GMFM, Short-term muscle power tests) [10]. In the present study Kinesio Tape was applied only for four weeks so, this difference in the study duration might also have affected the functional outcomes of the investigation and this can be confirmed by the results of Mazzone et al., study which investigated also the long term effects of taping; including 5 months of taping in conjunction with conventional physical therapy, followed by 7 months of physical therapy alone (taping wash-out), and other 5 months of taping plus therapy. Large improvements in the Melbourne assessment score were found in the first period in which taping was used and also in the second one, but not during the taping washout [11]. These results suggest that children with $\mathrm{CP}$ could benefit from the continuous correction provided by taping as no significance found during the taping wash out period.

This conclusion is similar to the conclusion of Bahadir et al., study which aimed to analyze the immediate effect of wrist correction Kinesio taping technique on hand span in children with cerebral palsy by applying buttonhole KT technique for assisting ROM of wrist extension. Wrist extension angle significantly increased after tape application

This could be due to the fact that Kinesio Taping have four major functions observed in practice. First, it supports the muscles by improving muscle contraction in weakened muscle, reducing muscle fatigue, over-extension and over contraction, reducing cramping and possible injury to muscle, increasing range of motion and reliving the pain. It also removes congestion to the flow of body fluids due to its ability to improve the blood and lymphatic circulation, reduce the excess heat and chemical substances in tissue, reduce inflammation and reduce the abnormal feeling and pain in skin and muscle. The third one is that Kinesio tape can activate endogenous analgesic system possibly by activating the spinal inhibitory system or activating the descending inhibitory system. At last, it corrects joint problems through adjusting the misalignment caused by spasm and shortened muscle, normalizing the muscle tone and abnormality of fascia in joints, improving range of motion and relieving the pain

We could find that the other studies investigate the immediate effects of kinesio taping on hand functions showed also significant results such as Demirel [14]. Keklicek et al., also investigated the immediate effects of thenar palmar tape application 
with and without pressure on upper extremity function in 45 children with cerebral palsy. Results showed positive effect of KT on the hand function [15]. A point to be considered here is that only Eleven CP children participated in the current study after excluding another four children. It seems that, the larger the study group is; the more accurate the results obtained as we see in Keklicek et al., study which involved 45 children [15] and Kara et al., study that involved 30 children [15]; both results were significant.

Also, Demirel and Tunay, aimed to determine active range of motion of the wrist after kinesio taping of the wrist extensor muscles in children with cerebral palsy. Inclusion criteria involved to be level 1 or 2 of the Manual Ability Classification System (MACS) and to have mild spasticity according to the Modified Ashworth Scale (MAS). After 45 minutes of application results showed statistically significant differences in wrist extension, radial, ulnar deviation active range of motion and wrist extension range of motion while functional ball grasping improved [16]. This study agrees with the present study in the inclusion criteria assessment tools as both used MACS and MAS to assess the children before including them in the study. A wide ranges were used (MACS: II, III or IV) in the present study; this could be considered as a cause for the insignificance of the results.

On other hand, studies which established to assess the short term effects of kinesio taping on hand functions in cerebral palsy children showed different results as Sadeghi et al., who investigated the short term effects of kinesio taping on 26 children (3-6 years old) with spastic diaplegic cerebral palsy for 12 days. Assessment tool was QUEST for evaluating quality of upper extremity skills and Modified Ashworth Scale for assessing spasticity of wrist before and after intervention in both groups. The results showed significance increase of total QUEST score and significance difference in domains of dissociated movements and grasp. However, there were no significant differences in weight bearing and protective extension domains [17]. Diplegia primarily affects the lower body, usually indicates the legs are affected more than the arms; while Hemiplegia indicates the arm and leg on one side of the body are affected. So, the upper limbs in diplegic CP children are less affected than in hemiplegic CP children; this should be taken in consideration [18]

Chitaria et al., also evaluated the short term effects of kinesio taping on fine motor function (PDMS) and active wrist extension Range of Mo- tion (ROM) in children with CP. By applying Kinesio tape on wrist extensors (lateral epicondyle of humerus to dorsal aspect of metacarpal head) for 3 days on 15 children with CP. Significant changes were found in fine motor but active ROM of wrist extension changed but these were not significant [19]. The current study used QUEST and PDMS to assess the participants before and after four weeks of the interventions. Four children show changes in the scores but unfortunately, these changes were not enough to be significant. This could be attributed to that a big change in the fine motor skills is needed to show significant results with PDMS and QUEST scales. Besides, using another assessment tools such as goniometer or tape record may help to detect this small changes in the hand functions. Also, the amount of tension applied, and the location, frequency, and duration of taping, lead to variations in its effectiveness.

Kinesio Tape can be applied to weak muscles to facilitate muscle contractions depending on tape application direction. When the tape is applied from the origin to the insertion of the muscle, as the muscle fibers contract, the tape adds support by pulling and stimulating the skin and muscle back to the point of origin. Conversely for cramping muscles caused by overuse and over-contraction, the tape is applied from the insertion of a muscle to its origin. As muscle fibers contract, the tape will relax and slack the muscle. By reducing spasm, normalizing muscle tone and balancing muscle length ratios, KT can ultimately serve to improve joint misalignment [20]

Therefore, therapists need to analyze the child's functional difficulties in relation to the aims of taping, and to state clearly the taping procedures used to solve the determined problems.

\section{Conclusion:}

This pilot study suggested that four weeks Kinesio taping was not effective in improving the hand functions of spastic hemiparetic cerebral palsy children. Further larger randomized controlled studies with longer duration are certainly needed to assess the short and long-term efficacy of kinesio taping on hand functions. Kinesio tape may be a promising technique to improve the hand functions of spastic hemiparetic cerebral palsy children if applied properly for enough period of time and combined with proper rehabilitation program.

\section{Conflict of interest:}

No conflict of interest in this study. 


\section{References}

1- ROSENBAUM P., PANETH N., LEVITON A., GOLDSTEIN M., BAX M., DAMIANO D.: A report: The definition and classification of cerebral palsy April 2006. Developmental Medicine \& Child Neurology, 109: 8-14, 2007.

2- BASU A.P., PEARSE J., KELLY S., WISHER V. and KISLER J.: Early intervention to improve hand function in hemiplegic cerebral palsy. Frontiers in neurology, 5: $281,2014$.

3- LEANNE S., JENNY Z. and ROSLYN B.: Systematic Review and Meta-analysis of Therapeutic Management of Upper-Limb Dysfunction in Children With Congenital Hemiplegia. Pediatrics, 123, 6: 1111-22, 2009.

4- GÜÇHAN Z. and MUTLU A.: The effectiveness of taping on children with cerebral palsy: A systematic review. Dev. Med. Child. Neurol., 59: 26-30, 2017.

5- KIM J.Y. and KIM S.Y.: Effects of kinesio tape compared with non-elastic tape on hand grip strength. Journal of Physical Therapy Science, 28 (5): 1565-8, 2016.

6- DeMATTEO C., LAW M., RUSSELL D., POLLOCK N., ROSENBAUM P. and WALTER S.: The reliability and validity of Quality of Upper Extremity Skills Test. Physical and Occupational Therapy in Pediatrics, 13 (2): 1-18, 1993.

7- KASE K.: Illustrated Kinesio taping, $4^{\text {th }}$ Ed. Ken Ikai Co Ltd, Tokyo, Japan, 2005.

8- KASE K., MARTIN P. and YASUKAWA A.: Kincsio Taping in Pediatrics, Fundamentals and Whole Body Taping Infant to Adolescent. Ken Ikai Co. Ltd, Tokyo, Japan, 2006.

9- CAMEROTA F., GALLI M. and CIMOLIN V.: Neuromuscular taping for the upper limb in cerebral palsy: A case study in a patient with hemiplegia. Dev. Neurorehabil., 17: 384-87, 2013

10- KAYA K.O., ATASAVUN U.S., TURKER D., KARAYAZGAN S., GUNEL M.K. and BALTACI G.: The effects of Kinesio Taping on body functions and activity in unilateral spastic cerebral palsy: A single-blind randomized controlled trial. Dev. Med. Child. Neurol., 57 (1): $81-8,2015$

11- MAZZONE S., SERAFINI A., IOSA M., ALIBERTI M.N., GOBBETTI T., PAOLUCCI S., et al.: Functional
Taping Applied to Upper Limb of Children with Hemiplegic Cerebral Palsy: A Pilot Study. Neuropediatrics, 42 (06): 249-53, 2011

12- BAHADIR A.Z., KARAYAZGAN S., MÜZEZZINOGLU O., YARAN M., ABAOGLU H. and AKEL S.: Effect of wrist correction kinesio taping application on hand span in children with cerebral palsy. Dev. Med. Child. Neurol., 57 (s4): 30, 2015.

13- KASE K., WALLIS J. and KASE T.: Clinical Therapeutic Applications of the Kinesio Taping Method, 2nd Ed. Ken Ikai Co Ltd, Tokyo, Japan, 2003.

14- DEMIREL A.: Assessment of S-EMG output before and after kinesio ${ }^{\circledR}$ tape application in children with hemiplegia 2010; http://tapingbase.info/en/assessment-of-s-emgoutput-before-and-after-kinesio-tape-application-inchildren-with-hemiplegia-en.

15- KEKLICEK H., UYGUR F. and YAKUT Y.: Effects of taping the hand in children with cerebral palsy. J. Hand Ther., 28: 27-33,2015

16- DEMIREL A. and TUNAY B.V.: The effect of kinesio tape on active wrist range of motion in children with cerebral palsy: A pilot study. Journal of Orthopedics, 6 (2): 69-74, 2014

17- SADEGHI M.R., LAJVARDI L., AMIRI A., TAGHI ZADEH G. and LOHRASBI S.: Investigating the effects of wrist Kinesio Taping on hand function of children with spastic diplegic cerebral palsy. J. Mod. Rehabil., 6 (1): 26-31, 2012.

18- BOYD R.N., MORRIS M.E. and GRAHAM H.K.: Management of upper limb dysfunction in children with cerebral palsy: A systematic review. Eur. J. Neurol., 8 (5): 150-66, 2001.

19- CHITARIA S.B., AMITESH N., SAILAKSHMI G. and BISWAS N.: Short-term effects of kinesiotaping on fine motor function in children with cerebral palsy-a quasiexperimental study. Crit. Rev. Phys. Rehabil. Med., 27 (1): 41-50, 2015.

20- CEPEDA J.P., FISHWEICHER A., GLEESON M., GREENWOOD S. and MOTYKA-MILLER C.: Does Kinesio Taping of the abdominal muscles improve the supine-to-sit transition in children with hypotonia? http://www.Kinesiotaping. com/Kinesio-tapingforabdominal-muscles-to-improve-the-supine-to-sittransition-inchildren. php. 2008. 


\section{تآثير إستخدام شريط الكينزو اللاصق على وظائف اليد اليد فى آطفال الخذلذ النصفى الذصى}

تهدف هذه الدراسة إلى تقييم فعالية شريط كينزف اللاصق بعد الإستخدام قصير المدى، وتآثيره على وظائف اليد خاصة القدرة

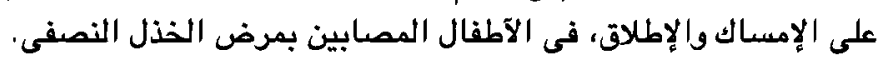

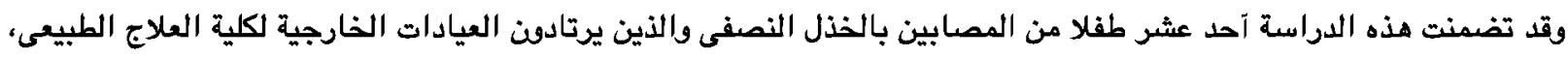

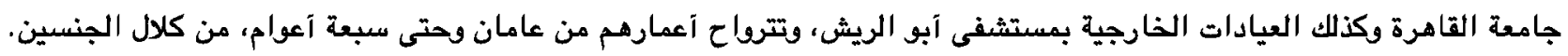

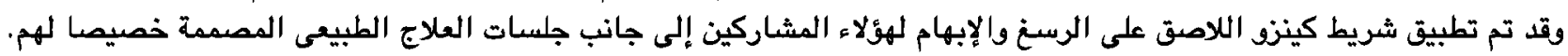

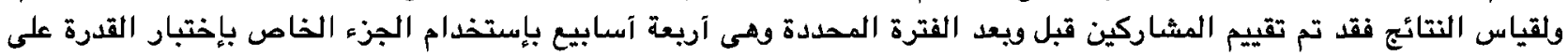

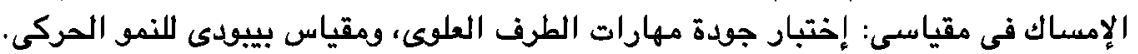

لم تظهر النتائج بعد آربعة آسايبع تحسن ملحوظ فى القدرة على الإمساك والإطلاق عند المشاركين قبل وضع شريط كينز اللاصق لهم وبعل وضعه.

آظهرت الدراسة الحالية آن شريط كينزو اللاصق قد لا يكن له مستقبل واعد فى علاج حالات الثلل الثقى التشنجى عند الآطفال، ولكن

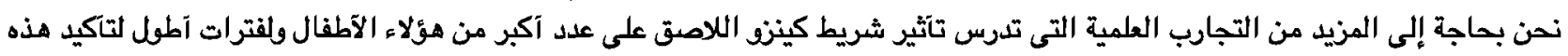

